Article

\title{
Business Processes and Comfort Demand for Energy Flexibility Analysis in Buildings
}

\author{
Stylianos K. Karatzas *, Athanasios P. Chassiakos and Anastasios I. Karameros \\ Department of Civil Engineering, The University Campus of Patras (Rion), 26504 Patras, Greece; \\ a.chassiakos@upatras.gr (A.P.C.); akarameros@upatras.gr (A.I.K.) \\ * Correspondence: stylianos.karatzas@upatras.gr; Tel.: +30-6972649610
}

Received: 13 November 2020; Accepted: 8 December 2020; Published: 12 December 2020

\begin{abstract}
Occupant behavior and business processes in a building environment constitute an inseparable set of important factors that drives energy consumption. Existing methodologies for building energy management lag behind in addressing these core parameters by focusing explicitly on the building's structural components. Additional layers of information regarding indoor and outdoor environmental conditions and occupant behavior patterns, mostly driven by everyday business processes (schedules, loads, and specific business activities related to occupancy patterns and building operations), are necessary for the effective and efficient modeling of building energy performance in order to establish a holistic energy efficiency management framework. The aim of this paper was to develop a context-driven framework in which multiple levels of information regarding occupant behavior patterns resulting from everyday business processes were incorporated for efficient energy management in buildings. A preliminary framework evaluation was performed in a multifaceted university building involving a number of spaces, employees, business processes, and data from sensors and metering devices. The results derived by linking operational aspects and environmental conditions (temperature, humidity, and luminance) to occupant behavior underlying business processes and organizational structures indicated the potential energy savings: a max of $7.08 \%$ for Heating, ventilation, and air conditioning (HVAC), $19.46 \%$ for lighting and a maximum of $6.34 \%$ saving related to office appliances.
\end{abstract}

Keywords: energy; demand; flexibility; business process; buildings; comfort; savings

\section{Introduction}

Energy efficiency is considered to be a critical part of the European energy strategy supporting the key targets of the European Union (EU) 2020 energy policy. Buildings are a significant part of the urban ecosystem, which accounts about $40 \%$ of the European energy requirements [1]. The $80 \%$ of the energy consumed within buildings applies during their operational phase [2], while $70 \%$ of this amount derives from occupant behaviors and automated control decisions related to the business processes hosted and executed according to the building's operational plans [3].

An important aspect contributing to the variability of energy consumption in buildings is the management of the activities carried out in the building. Operational activities are an integral part of business processes, accounting for more than $30 \%$ of total energy consumption [4]. Several studies have shown that the measurement of buildings' energy consumption is highly unstable even among buildings with the same types of functions in a similar geographical environment. Among the various factors contributing to this variability is the behavior of end-users in the processes conducted in the building $[1,5-8]$.

In addition to business processes, emphasis needs to be placed on end-user comfort conditions and their impact on energy consumption. Studies have shown that, given the modern trend towards 
low-energy buildings, it is imperative that end-users actively participate in achieving high energy efficiency goals without compromising their comfort or productivity [9-14]. Many studies have deduced that the behavior of people can have a significant impact on energy consumption and result in energy savings by people with little or no impact and without the disruption of the peoples' everyday living [15].

It has become apparent that various interrelated factors, allied to the structural elements of buildings (architectural, electrical, and mechanical characteristics), environmental conditions (outdoor and indoor), and (mainly) end-user behaviors (based on day-to-day business processes) determine and strongly affect building energy performance. In this context, the analysis of business processes in a building environment of the tertiary sector and their integration into an energy management framework is an issue of high interest.

In this article, we discuss important considerations in the development of the research hypothesis that a realistic view over the organizational energy performance is achieved when buildings are treated not as passive entities but rather as hosts of occupants executing activities that are aligned with the building energy data.

Existing building energy management practices mostly focus on building structural elements and rarely incorporate the information from the activities' users may perform. Reviewing existing methodologies and tools to support smart buildings [16-18] indicated that most of them do not:

- Capture the current performance of a building since they are based on unrealistic simulated data.

- Assess the performance of a building in detail since the analysis is performed on the basis of cumulative data.

- Consider the human factor as basic a parameter affecting energy consumption.

- Assess energy efficiency on homogeneous indicators instead of on heterogeneous ones.

- Propose energy-saving solutions in the day-to-day operation of the building.

- Take user data into account for dynamically adapting energy efficiency strategies.

Occupant behavior, a key driver of building performance, is usually represented [19] by pre-defined, static schedules or fixed rules that cannot represent the dynamics of users' energy behavior.

This paper proposes a context-driven energy management framework focusing on human factors and business processes hosted in the building. The major innovation of the proposed framework is that it considers the relationship between the major load types with the activities in a building, developing a linkage between energy management and organizational structures. Consequently, valuable knowledge can be gained on how everyday actions affect energy consumption, as well as how much users can potentially improve their energy consuming habits.

A bottom-up processing was adopted to incorporate the different modeling parameters in a holistic energy management concept. Then, an assessment was performed by highlighting the high and low-efficiency areas based on the estimation of energy-saving potential through the introduction of comfort and business process-related parameters. The interrelation of occupants with the environmental conditions was a core element of the modelling framework for the extraction of users' profiles, in terms of human preference boundaries through the monitoring of environmental context and device operational characteristics with the use of sensors and smart meter equipment. The identification of energy-saving potential acts as guidance for developing, setting-up, and implementing energy efficiency strategies and actions.

\section{Materials and Methods}

\subsection{Methodology}

Most of the current building energy management methodologies mainly focus on the building's structural characteristics and rarely use informative data extracted from the building users and their activities. A semantically enhanced energy management framework that incorporates the role 
of occupants and processes in the building environment in the analysis by using business process management (BPM) techniques is proposed in this work. The proposed energy management framework consists of three parts (Figure 1) that are explained below.
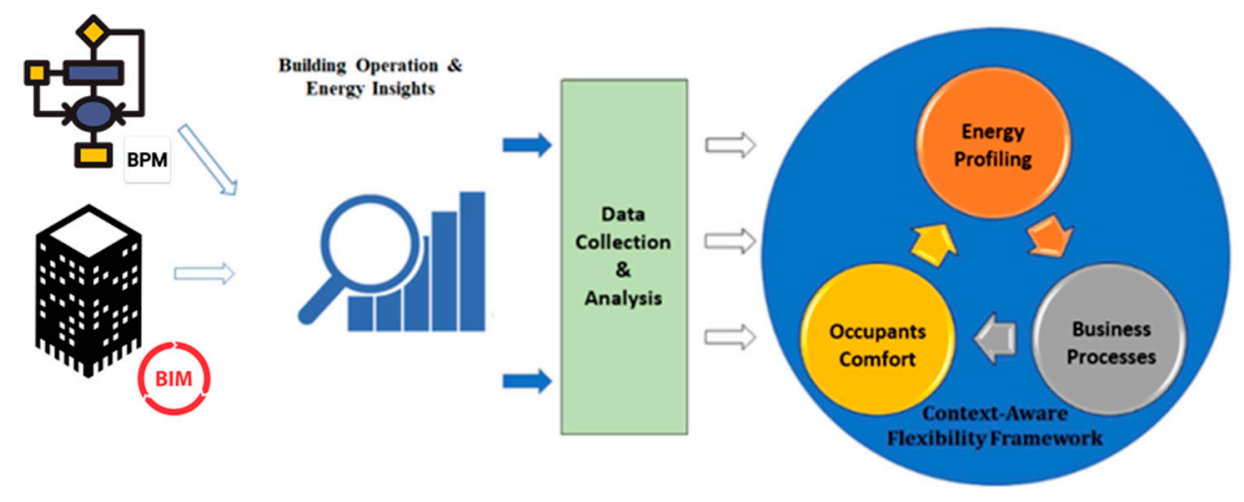

Figure 1. General energy management framework. BPM: business process management; BIM: building information modeling

In the first step of the framework, the initial energy status of the building was captured as a baseline. One of the basic activities in this stage was the extraction of an Extensible Markup Language (XML) model of the building for recording information of the building by using building information modeling (BIM) tool, which stands as the digital representation of the physical and functional characteristics of a building and constitutes a source of knowledge and information. In this study, the XML protocol was enhanced to incorporate new features derived from the correlation of individual devices and information for energy consumption. Therefore, the new XML model converted multi-layer information to facilitate human-centered energy management based on device operation. The process consisted of the following steps: 1 . develop the building model and extract the basic XML file with building's information; 2 . semantically enrich the XML with device operational characteristic information; and 3. develop an Entity-Relationship (ER) information model (Figure 2) based on the enriched XML model. In the ER model, new information regarding the business processes hosted in the building, such as devices with their operational characteristics, building zones defined according to the environmental conditions, and users and their organizational roles, were added [20].

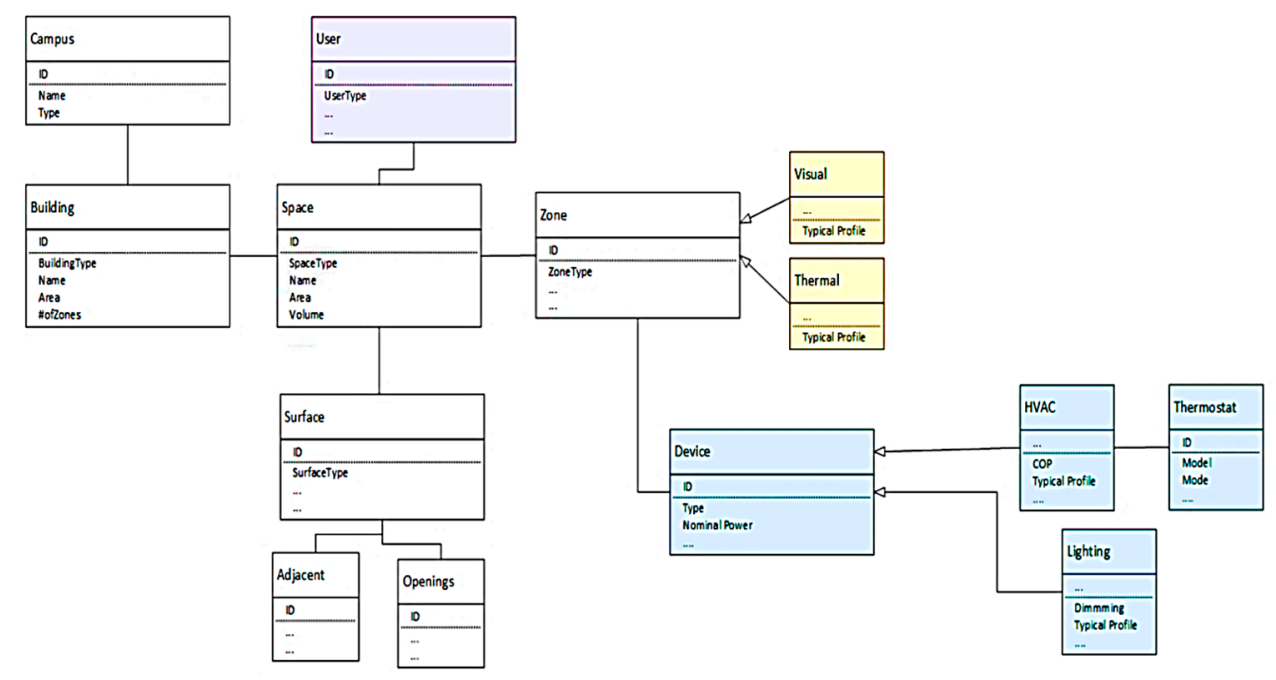

Figure 2. Entity-Relationship model.

The data collection and analysis layer was the second part of the proposed framework, drilling into details of building operations and providing access to diverse real-time information 
(sub-metering consumption and environmental conditions) in order to understand the driving factors of energy behavior.

A network of off-the-shelf low-cost meters, sensors, and actuators were deployed to monitor energy and context performance parameters of buildings (and consequently activities), focusing on several types of information: (a) controllable and flexible DERs (distributed energy resources), such as HVAC and lighting; (b) office equipment; and (c) environmental sensors to measure ambient conditions such as luminance and temperature.

We developed a flexibility framework where information from the different layers of the building organization regarding consumption devices and equipment, environmental conditions (outdoor and indoor), and occupant behavior patterns driven by everyday business processes (schedules, loads, and specific business episodes related to occupancy patterns and building operations) were incorporated into the effective and efficient management of building energy performance. Different types of analytics, time series, and model-based analytics were performed for the extraction of baseline performance, while the availability of sub-metering data with a high spatiotemporal granularity was a driving factor for the establishment of an accurate and reliable energy baseline framework on the basis of energy service verification in real-time. Furthermore, by combining information about indoor environmental conditions, the baseline analysis could be extended to address the various performance aspects evolving around the human factor. Details about the different types of analytics applied in this concept are presented in the following section.

\subsection{Context Aware Flexibility Framework}

The three interlinked components of the flexibility framework, as presented in the general methodology, are analyzed in this section in order to seize the potential of energy savings while considering comfort and business process-related constraints.

\subsubsection{DER Modeling and Energy Profiling}

In this section, the detailed modeling principles for the extraction of the energy profiles are presented with the focus being at the different loads examined: lights, HVAC and (other) plug devices. The analysis was performed by taking the device operational characteristics (e.g., the status) and the associated environmental conditions into account.

The light device model describes consumption as a function of the condition and dimming levels. Consequently, learning a light device's DER model is based on the correlation of consumption values with various device status characteristics and dimming levels. The following equation defines the consumption of a lighting device:

$$
\text { Poutput }=\text { Nominal_P } \times \text { Status } \times \text { Dim_Level, }
$$

where Poutput is the device energy consumption (in W), Nominal_P is the nominal power of the device (in $\mathrm{W})$, Status rests on a Boolean parameter (ON/OFF), and Dim_Level corresponds to the dimming level (\%).

Furthermore, the effect of lighting units on the visual comfort conditions was evaluated. More specifically, the disaggregation of illuminance levels on ambient luminance and luminance increase from lighting devices was examined in order to show the impact of the lighting device in total illuminance level:

$$
\mathrm{Wj}(\mathrm{t})=\sum_{n=1}^{M} H_{j, n} \times U_{n}+p_{j}(t)
$$

where $p_{j}(t)$ is the average value of illumination contributed to the $j$-th zone due to outdoor daylight at time $t$ and $H_{j, n}$ is the average value of illumination of the $j$-th zone when the $n$-th device is at its maximum and all others are off (Figure 3). 


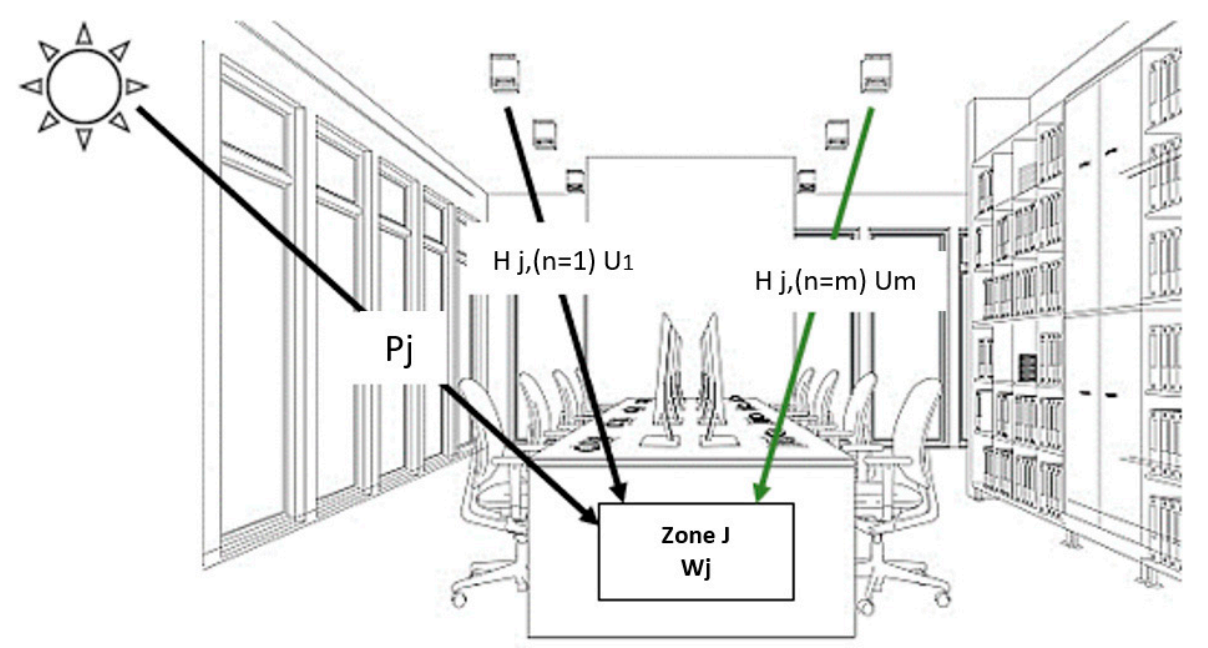

Figure 3. Lighting device impact on total illuminance level. Wj: total illuminance level; Pj: the average value of illumination contributed to the $j$-th zone due to outdoor daylight at time $\mathrm{t} ; \mathrm{Hj}, \mathrm{n}$ : the average value of illumination of the $j$-th zone when the $n$-th device is at its maximum and all others are off.

The updated DER model can then be described by: (a) a load schedule as a function of dimming level and condition and (b) the impact of dimming on illuminance level as a process-based function [21].

The HVAC device model for energy consumption adopted the concept of modeling and supervising thermostatically controlled loads (TCLs), which are to be included in Demand Side Management (DSM) strategies. In this model, there was a distinct correlation of power demand with set-point, status (ON/OFF), and ambient temperature (outdoor) and indoor temperature conditions. At first, the consumption of an AC (converter) unit was correlated in real-time with the standard operation mode of a heat pump unit (compressor ON/OFF plus ventilation unit consumption). The temperature change $\theta(t)$ attributed to a thermostatically controlled load at cooling state could be used, according to Bomela et al. [22], by a discrete time difference model:

$$
\Theta(t+1)=\frac{e-1}{R \times C} \times \Theta(t)+\frac{1-(e-1)}{R \times C} \times[\Theta(a m b)-P \times R],
$$

where $\Theta\left(\mathrm{amb}\right.$ ) is the ambient temperature (in ${ }^{\circ} \mathrm{K}$ ), $\mathrm{R}$ is the thermal resistance (in ${ }^{\circ} \mathrm{K} / \mathrm{kW}$ ), $\mathrm{C}$ is the thermal capacitance (in $\mathrm{KWh} /{ }^{\circ} \mathrm{K}$ ), and $\mathrm{P}$ is the energy demand of the TCL when it is in the ON state. In cooling periods and in steady-state, the HVAC consumes from temperature $\theta+$ to temperature $\theta-$, an approach that is also considered during heating period where the power factor is set as -P. Hence, the final temperature calculation is associated with indoor air temperature, ambient/outdoor air temperature, and configuration criteria (C, P, R, and set-point), while, at the same time, the learning mechanism considers estimations of $C$ and $R$ for the different building zones by using the least-squares regression technique. The model presented above correlates energy characteristics with their environmental impact.

Finally, the model for the plug devices was incorporated in the analysis. Plug devices are not associated with environmental conditions, and, thus, an overall DER profile is characterized by its power profile and the nominal operating characteristics. The equation presented below expresses the lighting device consumption [23]:

$$
\text { Poutput Nominal_P } \times \text { Status } \times \text { State_Level, }
$$

where $P_{\text {output }}$ is the device consumption (in W), Nominal_P is the device nominal power (in W), Status is a Boolean parameter with an ON/OFF status, and State Level is the operational level of the device. 


\subsubsection{Occupant Comfort Profiling}

A comfort profiling framework was proposed in order to achieve a repeated and simultaneous analysis of events captured based on real-time data feed. Data were analyzed to generate dynamic occupant behavioral profiles. Occupant profiles were specified as:

- "Context-based": the relationship of occupant actions with indications related to comfort under distinct environmental conditions.

- "Pattern-based": they adapt to seasonal patterns according to the information captured from sensors.

The behavioral profiles of occupants were the reference points in order to identify and quantify the boundaries and cost of users' comfort in real-time in terms of excess energy consumption, comfort preferences, and no preferences of occupants. Two main categories related to events were analyzed: (1) occupancy events: information of presence; and (2) environmental events: alteration in the room environmental conditions with focus on temperature and luminance. The comfort profiling engine analyzed actions under specific ambient conditions using a probabilistic framework to extract correlations between events and produce personalized comfort/discomfort indicators to develop user dynamic profiles. The formalism can be generalized as follows:

$$
\operatorname{Pr}(\text { Disc } \mid \text { Envir })=\frac{\operatorname{Pr}(\text { Disc } \times \text { Envir })}{\operatorname{Pr}(\text { Envir })}
$$

where $\operatorname{Pr}$ (Disc| Envir) is the discomfort level during specific environmental conditions, Pr (Envir * Disc) is the environmental state probability for a specific discomfort level indication, and $\operatorname{Pr}$ (Envir) is the state probability being at a specific environmental condition.

The abovementioned formula calculates the probability of an occupant being uncomfortable while living in specified ambient conditions, having the probabilities of indoor conditions where the occupant feels (dis)comfort as facts. These probabilities could be estimated either on a real-time basis or from the utilization of historical data. The first one corresponds to a real case and scenario, and the second corresponds to the experimental conditions where environmental data are collected from user premises just to observe the environmental-related adjustment actions in a specific case. In order to highlight the way of annotating user discomfort for the environmental conditions, a sample of historical data was taken into account. It was assumed that if an occupant is present and not reacting to current environmental conditions, this is an indication of him/her being in comfort. This information was considered to be of high value due to the fact that it was used to analyze the occupant tolerance to environmental variations, a metric that is hard to directly capture.

For the determination of comfort boundaries, the predicted mean vote (PMV) methodology Figure 5.2.1.2 in [24] for extracting a comfort curve was adopted. Based on this, PVM predicted the average vote of a large group of people on a seven-point thermal sensation scale, with min-max boundaries of $[-3,+3]$. For the scope of this research, the associated acceptable thermal comfort boundaries were set to min and max values of $[-0.75,+0.75]$, respectively, at $25 \%$ of probability density function (PDF).

\subsubsection{Business Process Analysis}

A key principle for the proposed framework was the adoption of a business process-driven modeling approach and its incorporation into the overall framework in order to provide insights into the consumption patterns in the building environment. The overall analysis did not need to be firmly attached to the detailed operational steps; rather, a more abstract and aggregated approach needed to be adopted in the aim of modeling the behavior of occupants in an enterprise environment.

Another important aspect of the proposed approach was its ability to periodically adapt model parameters to the continuously evolving building and operational conditions. As a business organization 
evolves, business processes and related parameters may change, and, thus, model re-organization is required. Through continuous monitoring through a wireless sensor network, indoor contextual and occupancy (presence/absence, device usage, etc.) activity-related parameters could be inferred and further incorporated into the enhanced business operational model. A data-driven training framework was established to analyze streams of data and extract knowledge related to user activities in premises.

As a final remark, the proposed approach for the development of a business activity model did not stand as a static procedure; instead, it incorporated the dynamic attributes of business operations that affect the overall energy consumption and performance of a building organization.

\subsubsection{Context-Aware Demand Flexibility Profiles}

On the basis of the individual models of the proposed framework presented earlier, an interrelated process could take place to extract the context-aware demand flexibility profiles. The overall idea was to combine DER energy profiles with the building's environment context (occupants' comfort profiles and business processes) in order to estimate the load controllability potential, which is expressed in terms of flexibility. A detailed analysis was performed for the different device types examined in the pilot. A visual representation of this framework is depicted in Figure 4.

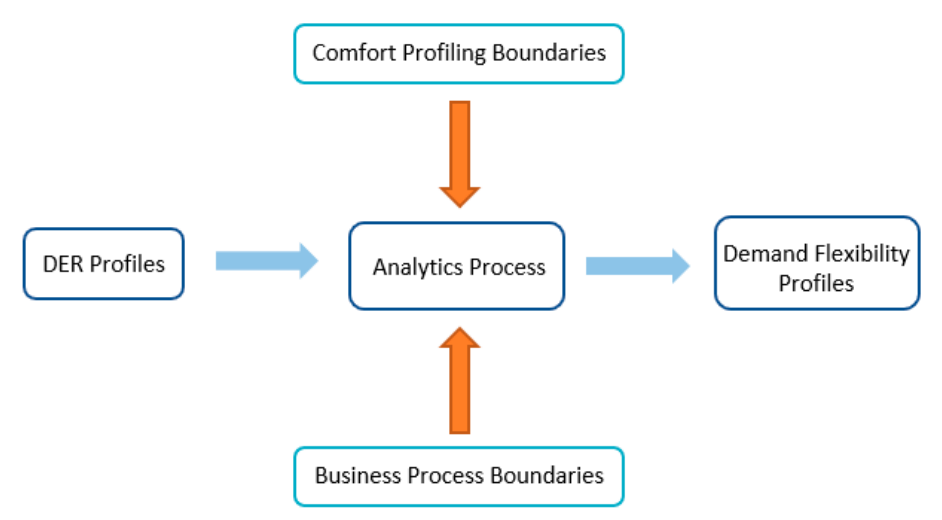

Figure 4. Demand flexibility profile analysis process. DER: distributed energy resource.

The underlying logic of the process, which is described in Figure 5, was that if the comfort requirements were satisfied and there was still a potential for controllability, then control actions related to loads that directly impact the consumption level could be triggered. For this analysis, technical issues and constraints (e.g., controllability level of light devices) were incorporated into the analysis.

Visual comfort conditions were interlinked with the light device profiles, as defined above, aiming at extracting the flexibility profiles of individual devices. More specifically, considering the actual and the acceptable comfort conditions, as well as the actual consumption data, the ideal usage profile could be extracted, which led to the calculation of demand flexibility as the difference between the actual consumption and the consumption corresponding to comfort boundaries (ideal consumption).

Similar to light devices, thermal comfort conditions were interlinked with the HVAC device profiles, aiming at of extracting the flexibility profiles of individual devices. Considering again the actual and the acceptable comfort conditions, as well as the actual HVAC device operation, a potential HVAC profile could be extracted while fully preserving indoor environmental conditions and preferences. This correlation analysis led to the calculation of demand flexibility as the difference between the actual and the ideal consumption. The algorithmic processes for calculating the visual and thermal comfort demand flexibility are presented in Appendix A (Figure A1).

The identified business processes were associated with the light device profiles for the extraction of business process-related demand flexibility. By analyzing the processes that took place in the building environment, working and non-working hours were derived. By further correlating this information with the light device profiles, useful information about the vampire power use of devices, i.e., device use during absence hours, could be extracted. Consumption in non-operational hours 
(off-time consumption-consumption when a business process is not performed) is an indication of energy waste/vampire power load, with the margin for energy savings expressed in terms of flexibility.

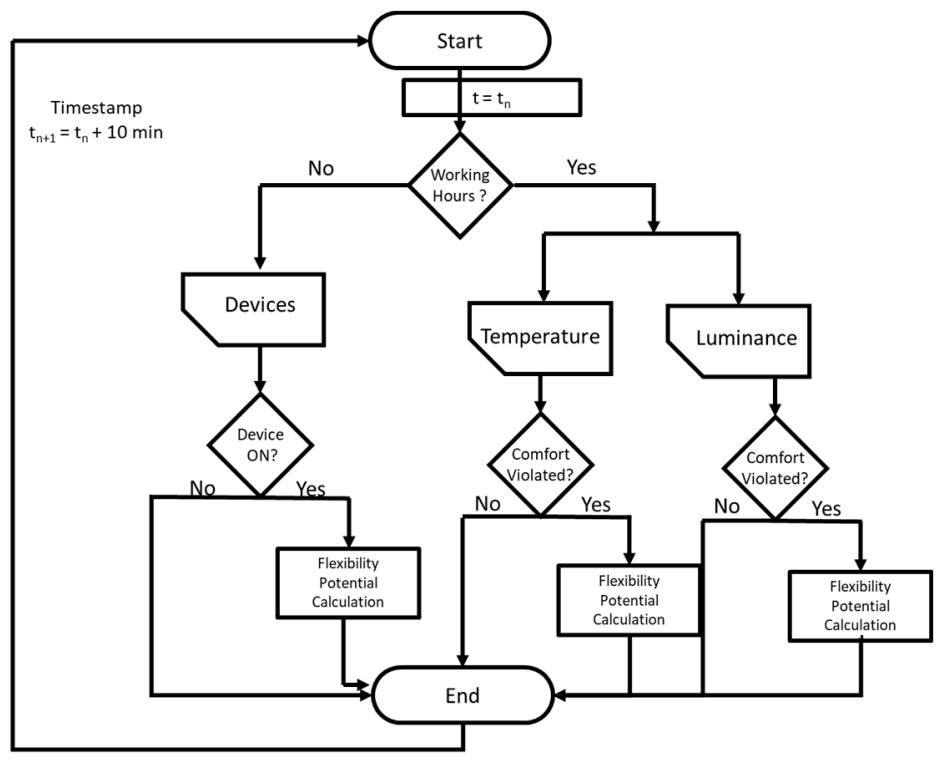

Figure 5. Flexibility analysis process.

For the office devices, the identified business processes were interrelated to the plug device energy profiles for the extraction of business process-related demand flexibility. By analyzing the processes that took place in the building environment, working and non-working hours were derived from the analysis. By further correlating this information with the plug device profiles, useful information about vampire use of devices (during non-working hours) was obtained. The algorithmic processes for calculating the lighting and office device flexibility are presented in Appendix A (Figure A2).

\section{Results}

\subsection{Pilot Site Demonstration and Evaluation}

\section{Pilot Site Description}

The evaluation of the proposed framework was performed based on a real-life demonstration that included multifaceted building in the campus of the University of Patras that consisted of eight offices (Figure 6). The XML model of the building was extracted and enhanced to include users, devices, and process-related information (Appendix B). Each office was considered as one zone, within which several users and their work processes were hosted. The load types and the metering installation applied in the pilot case are presented in Tables 1 and 2, respectively.

Table 1. Installation load types.

\begin{tabular}{|c|c|}
\hline \multicolumn{2}{|r|}{ Offices } \\
\hline Illumination & $16 \times$ luminaries with $4 \times 18 \mathrm{~W}$ fluorescent lamps \\
\hline Air conditioning & 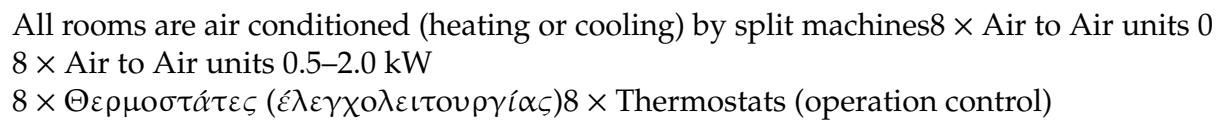 \\
\hline Office devices & $\begin{array}{l}17 \times \text { screens, computers } \\
10 \times \varepsilon \kappa \tau v \pi \omega \tau 10 \times \text { printers }\end{array}$ \\
\hline
\end{tabular}




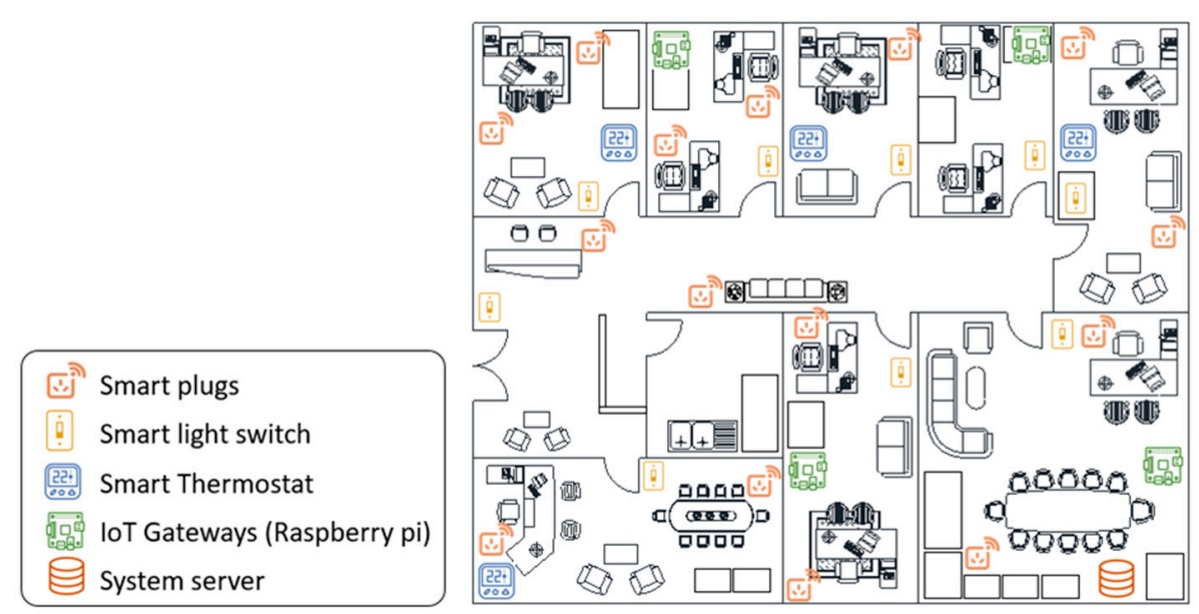

Figure 6. Pilot site overview.

Table 2. Metering equipment.

\begin{tabular}{ccc}
\hline & \multicolumn{2}{c}{ Offices } \\
\hline Load & Controller & Functionality \\
\hline Illumination & $8 \times$ Z-Wave Universal Dimmer & ON/OFF, dimming level, consumption metering \\
\hline \multirow{2}{*}{ Air conditioning } & $8 \times$ Z-Wave to IR Extender & ON/OFF, operational mode, state \\
\cline { 2 - 3 } & $8 \times$ Z-Wave Smart Plugs & Consumption metering \\
\hline Office devices & $27 \times$ Z-Wave Smart Plugs & ON/OFF, consumption metering \\
\hline
\end{tabular}

For the alpha testing phase, consumption raw data (10-min level granularity) for heating, lighting, and office devices (Online Resource 1) were extracted for a time period of one month, and the values of total consumption per zone for one month, the daily average consumption, and the maximum day consumption occurred within this period are presented in Table 3. The environmental data, temperature, and luminance (Online Resource 2) were extracted for a one-month period time and are presented in Table 4.

Table 3. HVAC, lighting and device consumption (1-month period).

\begin{tabular}{ccccc}
\hline Office & Zone & Total $\mathbf{( W h})$ & Daily Average $\mathbf{( W h )}$ & Max (Wh) \\
\hline \multirow{3}{*}{ Research Offices } & \multicolumn{3}{c}{ HVAC } & \\
& 1 & 185.380 & 7.415 & 10.260 \\
\cline { 2 - 5 } & 2 & 241.750 & 9.500 & 13.250 \\
\cline { 2 - 5 } & 3 & 270.500 & 10.820 & 13.500 \\
\hline \multirow{2}{*}{ Public Transaction Offices } & 4 & 182.560 & 7.302 & 8.736 \\
\cline { 2 - 5 } & 6 & 64.960 & 2.598 & 3.136 \\
\hline \multirow{2}{*}{ Administration Offices } & 7 & 285.600 & 11.424 & 13.888 \\
\cline { 2 - 5 } & 8 & 149.001 & 5.960 & 7.481 \\
\hline
\end{tabular}


Table 3. Cont.

\begin{tabular}{|c|c|c|c|c|}
\hline Office & Zone & Total (Wh) & Daily Average (Wh) & $\operatorname{Max}(\mathrm{Wh})$ \\
\hline \multicolumn{5}{|c|}{ Lighting } \\
\hline \multirow{4}{*}{ Research Offices } & 1 & 78.348 & 3.730 & 13.558 \\
\hline & 2 & 70.308 & 3.515 & 5.757 \\
\hline & 3 & 57.671 & 2.507 & 5.082 \\
\hline & 4 & 53.740 & 2.559 & 5.759 \\
\hline \multirow{2}{*}{ Public Transaction Offices } & 5 & 72.033 & 2.881 & 4.367 \\
\hline & 6 & 61.919 & 2.948 & 4.516 \\
\hline \multirow{2}{*}{ Administration Offices } & 7 & 75.877 & 3.793 & 6.382 \\
\hline & 8 & 61.495 & 2.795 & 4.109 \\
\hline \multicolumn{5}{|c|}{ Office Devices } \\
\hline \multirow{4}{*}{ Research Offices } & 1 & 105.420 & 3.400 & 6.780 \\
\hline & 2 & 79.962 & 2.855 & 6.578 \\
\hline & 3 & 54.600 & 1.761 & 4.363 \\
\hline & 4 & 44.875 & 1.495 & 4.635 \\
\hline \multirow{2}{*}{ Public Transaction Offices } & 5 & 80.035 & 2.581 & 10.842 \\
\hline & 6 & 74.852 & 2.495 & 10.810 \\
\hline \multirow{2}{*}{ Administration Offices } & 7 & 66.956 & 2.159 & 11.072 \\
\hline & 8 & 47.509 & 1.532 & 3.513 \\
\hline
\end{tabular}

Table 4. Temperature and luminance data.

\begin{tabular}{|c|c|c|c|c|}
\hline Office & Zone & $\begin{array}{c}\text { Average } \\
\text { (for One Month) }\end{array}$ & Min & Max \\
\hline \multicolumn{5}{|c|}{ Temperature $\left({ }^{\circ} \mathrm{C}\right)$} \\
\hline \multirow{4}{*}{ Research Offices } & 1 & 19.65 & 15.4 & 23.7 \\
\hline & 2 & 21.6 & 16.2 & 24.5 \\
\hline & 3 & 21.26 & 18.4 & 24.4 \\
\hline & 4 & 20.55 & 16.1 & 23.9 \\
\hline \multirow{2}{*}{ Public Transactions Offices } & 5 & 20.2 & 16.7 & 23.8 \\
\hline & 6 & 21.7 & 17.6 & 24.3 \\
\hline \multirow{2}{*}{ Administration Offices } & 7 & 22.3 & 17.1 & 25.7 \\
\hline & 8 & 21.7 & 16.2 & 24.7 \\
\hline \multicolumn{5}{|c|}{ Luminance (lux) } \\
\hline \multirow{4}{*}{ Research Offices } & 1 & 74.58 & & 212 \\
\hline & 2 & 65.68 & & 182 \\
\hline & 3 & 55.92 & & 250 \\
\hline & 4 & 68.70 & & 191 \\
\hline \multirow{2}{*}{ Public Transactions Offices } & 5 & 82.40 & & 190 \\
\hline & 6 & 89.20 & & 500 \\
\hline \multirow{2}{*}{ Administration Offices } & 7 & 50.20 & & 325 \\
\hline & 8 & 57.40 & & 254 \\
\hline
\end{tabular}




\subsection{Pilot Results}

\subsubsection{Energy Profiling}

For lighting loads and office devices, weekly consumption profiles were analyzed to export user profiles (Online Resource 3). According to the analysis, the consumption of office equipment and lighting units corresponded to usage during operating hours, while the consumption of lighting units was also influenced by external environmental conditions (outdoor lighting conditions).

The daily operating profile of a printer in one is indicatively presented in Figure 7, which shows a clear definition of three discrete printer device states (following Equation (4)), namely the ON state indicated by consumption around the nominal phase of the device (500 W), the standby mode (around $60 \mathrm{~W})$, and the OFF elsewhere.

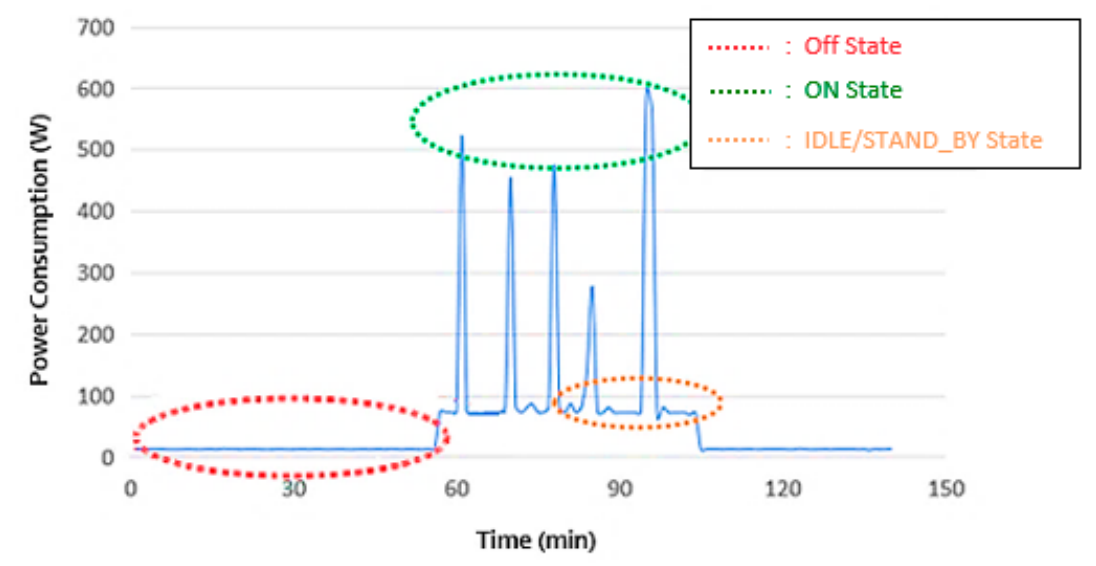

Figure 7. Printer consumption profile.

Figure 8 presents a diagram of power consumption for lighting along a full weekday period (based on Equation (1)), with the ON state corresponding to working hours and the OFF state to non-working hours or hours with no need to use electric lights. The consumption level (blue color-corresponding to power consumption indicated in the left side of the diagram) is shown to have decreased as the dimming level (red color-corresponding to dim \% level indicated in the right side of the diagram) increased. Indicatively, the consumption for the OFF status was $0 \mathrm{~W}$, the consumption for $100 \%$ dimming was $600 \mathrm{~W}$, and the consumption for $50 \%$ dimming was $300 \mathrm{~W}$ ( $0 \%$ dimming correlated to 0 power consumption).

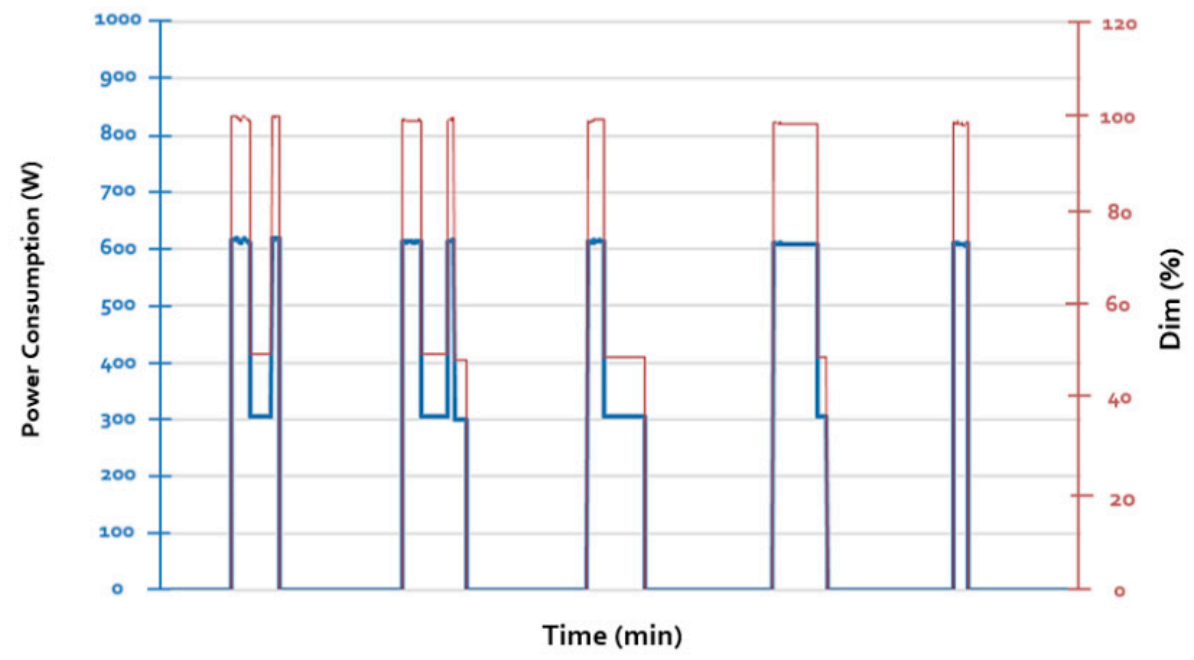

Figure 8. Lighting consumption profile with dimming (10-min level granularity). 
The heating consumption profile development required a detailed analysis, which consists of both:

a. A macroscopic analysis for the correlation of environmental conditions to heating consumption. Figure 9 indicates the heating consumption for a period of five weekdays and its correlation with external and internal environmental operating conditions, while Figure 10 indicates the correlation between heating consumption and indoor temperature conditions for a period of four weeks.

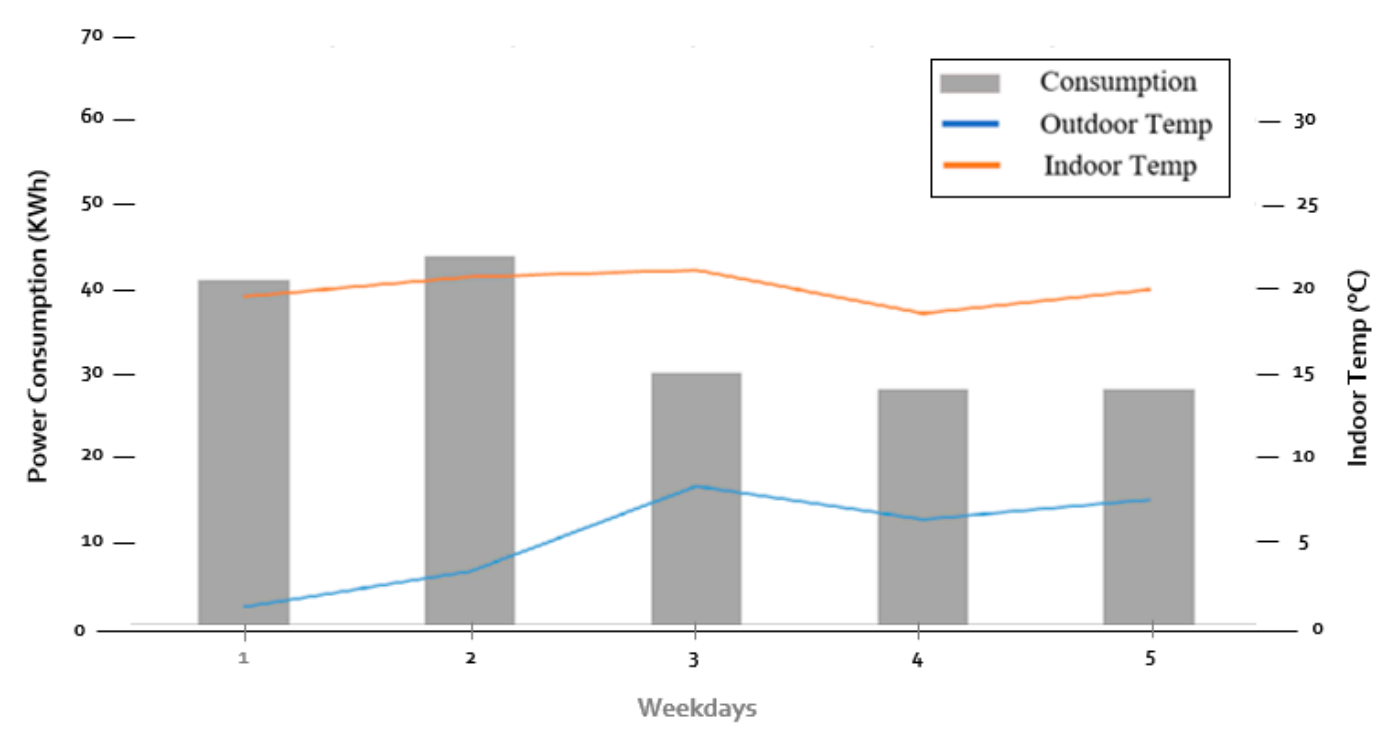

Figure 9. HVAC consumption-indicative macroscopic analysis.

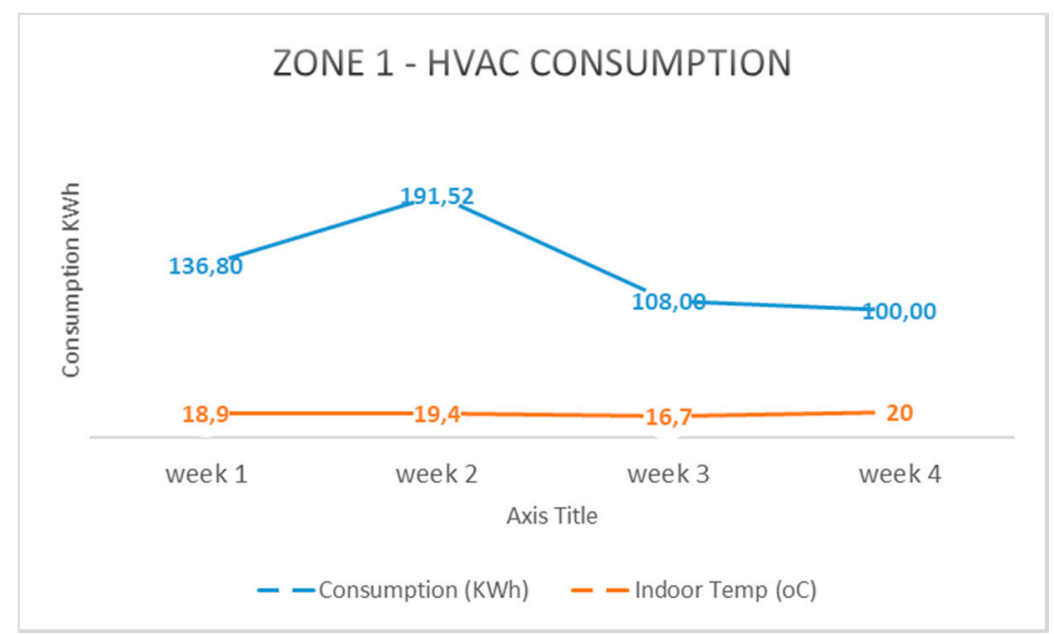

Figure 10. HVAC consumption—indoor temperature correlation.

b. A microscopic analysis to extract the operating profile of each individual device. In the context of microscopic analysis, capturing consumption over a period of $6 \mathrm{~h}$ (Figure 11) demonstrated the circular operation of a typical heat pump unit.

The consumption was plotted in real-time by the standard operation mode of a heat pump unit (compressor ON/OFF plus ventilation unit consumption). The relationship between the $\mathrm{ON}$ and OFF period time (T_off/T_on) remained constant in the operating cycle of the unit, given constant external environmental and process operational conditions. The consumption profile followed an incremental pattern rather than the above in the transition period of the unit (startup). 


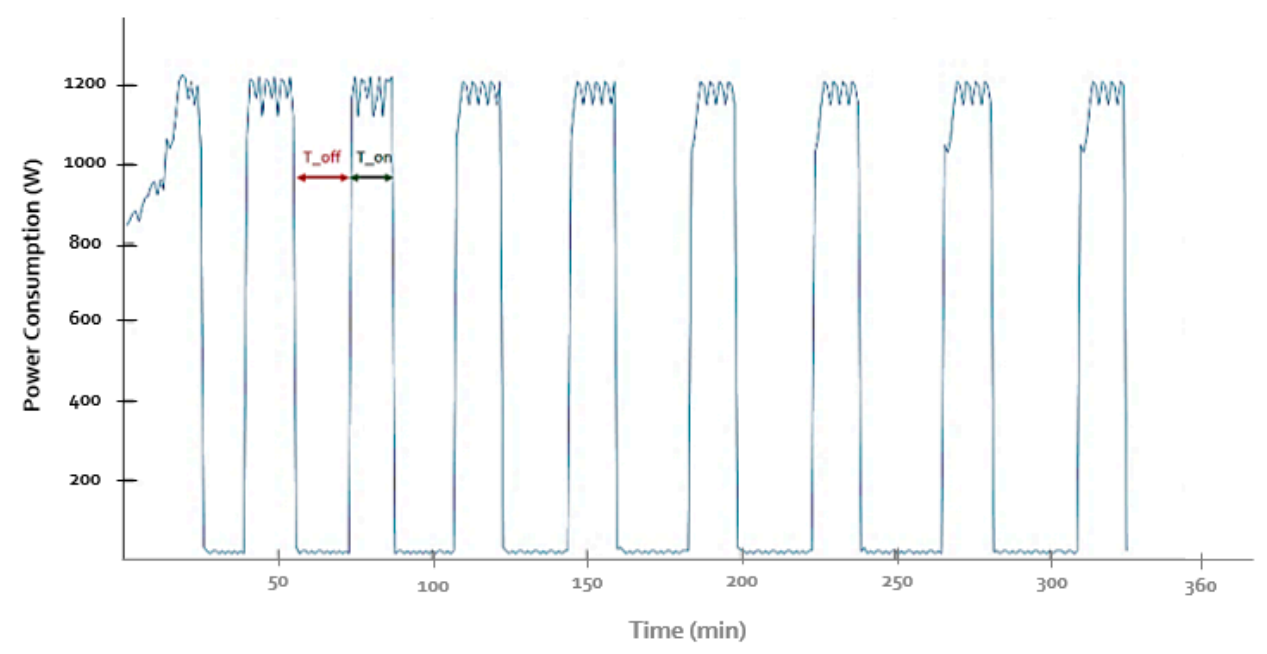

Figure 11. HVAC consumption—indicative microscopic analysis.

\subsubsection{Occupant Comfort Profiling}

The end-users' comfort boundaries in each zone were extracted from the statistical analysis of the environmental data measurements (using the bin and the occurrence frequency; Online Resource 4), and the results are shown in Table 5.

Table 5. Comfort boundaries.

\begin{tabular}{|c|c|c|c|}
\hline \multirow{2}{*}{ Office } & \multirow{2}{*}{ Zone } & \multicolumn{2}{|c|}{ Comfort } \\
\hline & & Visual (LUX) & Thermal $\left({ }^{\circ} \mathrm{C}\right)$ \\
\hline \multirow{4}{*}{ Research Offices } & 1 & $58^{\circ}$ & $19-21^{\circ}$ \\
\hline & 2 & $54^{\circ}$ & $21-23^{\circ}$ \\
\hline & 3 & 52 & $20.5-22.5^{\circ}$ \\
\hline & 4 & 78 & $20-22^{\circ}$ \\
\hline \multirow{2}{*}{ Public Transaction Offices } & 5 & $146^{\circ}$ & $18.5-21.5^{\circ}$ \\
\hline & 6 & $71^{\circ}$ & $21-23^{\circ}$ \\
\hline \multirow{2}{*}{ Administration Offices } & 7 & $70^{\circ}$ & $22-24^{\circ}$ \\
\hline & 8 & $81^{\circ}$ & $20.5-23.5^{\circ}$ \\
\hline
\end{tabular}

\subsubsection{Business Process Analysis}

Seventeen employees were employed altogether in the eight zones of the pilot site. The zones were classified into three categories: research offices, administrative offices, and public relations offices. Each profile in a zone corresponded to a specific cluster of users following the same process pattern. A list of the main business processes is presented in Table 6 as a composition of the individual business processes.

The analysis of energy consumption was made both vertically, i.e., considering $\mathrm{N}$ types of activities taking place in different spaces of a building (e.g., administration and research offices), and horizontally, i.e., considering each undergoing process in each one of the respective spaces involving multiple business roles (e.g., meeting attendance and printing tasks). The total consumption was a function of the operating hours of individual business processes and the consumption of individual devices during operation hours (Online Resource 9). The working hours of each office profile per business process were extracted from the staff themselves after recording their activities and were used to construct Table 7 . For zone $4,30 \%$ of the working hours were allocated to the meeting room, which accordingly translated to $30 \%$ of the consumption. 
Table 6. Business processes.

\begin{tabular}{|c|c|c|c|c|c|c|c|c|}
\hline \multirow[t]{2}{*}{ Office } & \multirow[t]{2}{*}{ Profile } & \multicolumn{2}{|c|}{ Consumption per Profile (Wh) } & \multicolumn{5}{|c|}{ Consumption (Wh) per Business Process } \\
\hline & & Zones & Consumption & Adm. Work & $\begin{array}{c}\text { Public } \\
\text { Attendance }\end{array}$ & Break & Print Task & $\begin{array}{l}\text { Bilateral } \\
\text { Meeting }\end{array}$ \\
\hline Research Offices & B & $2+4 \times 0.7$ & 588.844 & 529.298 & 0 & 33.081 & 6.616 & 19.848 \\
\hline $\begin{array}{c}\text { Public } \\
\text { Transactions } \\
\text { Offices }\end{array}$ & $\mathrm{C}$ & $5+6$ & 639.400 & 0 & $597,242.38$ & 35.131 & 7.026 & 0 \\
\hline \multirow{2}{*}{$\begin{array}{l}\text { Administration } \\
\text { Offices }\end{array}$} & $\mathbf{D}$ & 7 & 291.834 & 257.501 & 0 & 17.166 & 6.866 & 10.300 \\
\hline & $\mathrm{E}$ & 8 & 243.732 & 214.270 & 0 & 0 & 2.678 & 26.783 \\
\hline Meeting Room & MIX & $4 \times 0.3$ & 84.352 & & & & & \\
\hline
\end{tabular}

Table 7. Working hours per business process and office profile.

\begin{tabular}{ccccccc}
\hline Profiles & Admin Work & Public Attendance & Break & Print Task & Bilateral Meeting & Total \\
\hline A & 8 & 0 & 0.5 & 0.2 & 0.5 & 9.2 \\
\hline B & 8 & 0 & 0.5 & 0.1 & 0.3 & 8.9 \\
\hline C & 0 & 8.5 & 0.5 & 0.1 & & 9.1 \\
\hline D & 7.5 & 0 & 0.5 & 0.2 & 0.3 & 8.5 \\
\hline E & 8 & 0 & 0 & 0.1 & 1 & 9.1 \\
\hline
\end{tabular}

The consumption per business process (CBP) is presented in Table 8 and was calculated as:

$$
C B P j, i=C P j \times \text { Rate } i,
$$

where $\mathrm{CP}$ is the consumption per profile (extracted from Tables 3 and 7) and Rate is a value calculated based on Table 7 as:

$$
\text { Rate } i=\frac{\text { Working hours of Business Process }}{\text { Total working hours }},
$$

with $i$ from 1 to 5 referring to the number of business processes and $j=1-5$ referring to the profile number.

\begin{tabular}{|c|c|c|c|c|c|c|c|c|c|}
\hline \multirow[b]{2}{*}{ Zone } & \multirow[b]{2}{*}{ Profile } & \multicolumn{8}{|c|}{ Business Processes } \\
\hline & & $\begin{array}{l}\text { Check } \\
\text { In }\end{array}$ & Admin Work & $\begin{array}{c}\text { Public } \\
\text { Attendance }\end{array}$ & Break & $\begin{array}{c}\text { Meeting } \\
\text { Attendance }\end{array}$ & Print Task & $\begin{array}{l}\text { Bilateral } \\
\text { Meeting }\end{array}$ & $\begin{array}{c}\text { Check } \\
\text { Out }\end{array}$ \\
\hline \multirow{2}{*}{ Research Offices } & A & $10: 00$ & $\begin{array}{c}10: 00-14: 00 \text { and } \\
14: 30-19: 00\end{array}$ & - & $14: 00-14: 30$ & Rarely & $16: 00-17: 00$ & Rarely & 19:00 \\
\hline & B & $8: 00$ & $\begin{array}{c}8: 00-3: 00 \text { and } \\
13: 30-17: 00\end{array}$ & - & 13:00-13:30 & Rarely & Seldom & Rarely & $17: 00$ \\
\hline $\begin{array}{c}\text { Public } \\
\text { Transactions } \\
\text { Offices }\end{array}$ & C & 7:00 & - & $\begin{array}{c}7: 00-12: 00 \text { and } \\
12: 30-16: 00\end{array}$ & $12: 00-12: 30$ & - & Random & - & $16: 00$ \\
\hline \multirow{2}{*}{$\begin{array}{l}\text { Administration } \\
\text { Offices }\end{array}$} & $\mathrm{D}$ & 9:00-9:30 & $\begin{array}{c}9: 00-14: 00 \text { and } \\
14: 30-8: 00\end{array}$ & - & $14: 00-14: 30$ & Rarely & $15: 00-16: 00$ & Occasional & 18:00 \\
\hline & E & 9:00-9:30 & 9:30-19:00 & - & Random & Occasional & Seldom & Occasional & 19:00 \\
\hline
\end{tabular}

Table 8. Consumption per business process (Online Resource 8).

\subsubsection{Analytics Process}

From the analysis of energy profiles and occupant comfort preferences, comfort flexibility profiles were extracted (Online Resource 5). For example, the details of the lighting device of zone 1 within a three-day time horizon are shown in Figure 12. The consumption level (in red), the impact in luminance (in purple), and the visual comfort boundaries of the user (in green) led to the excess usage of lighting (marked) and thus the control the light DER without affecting the comfort boundaries of the users. 


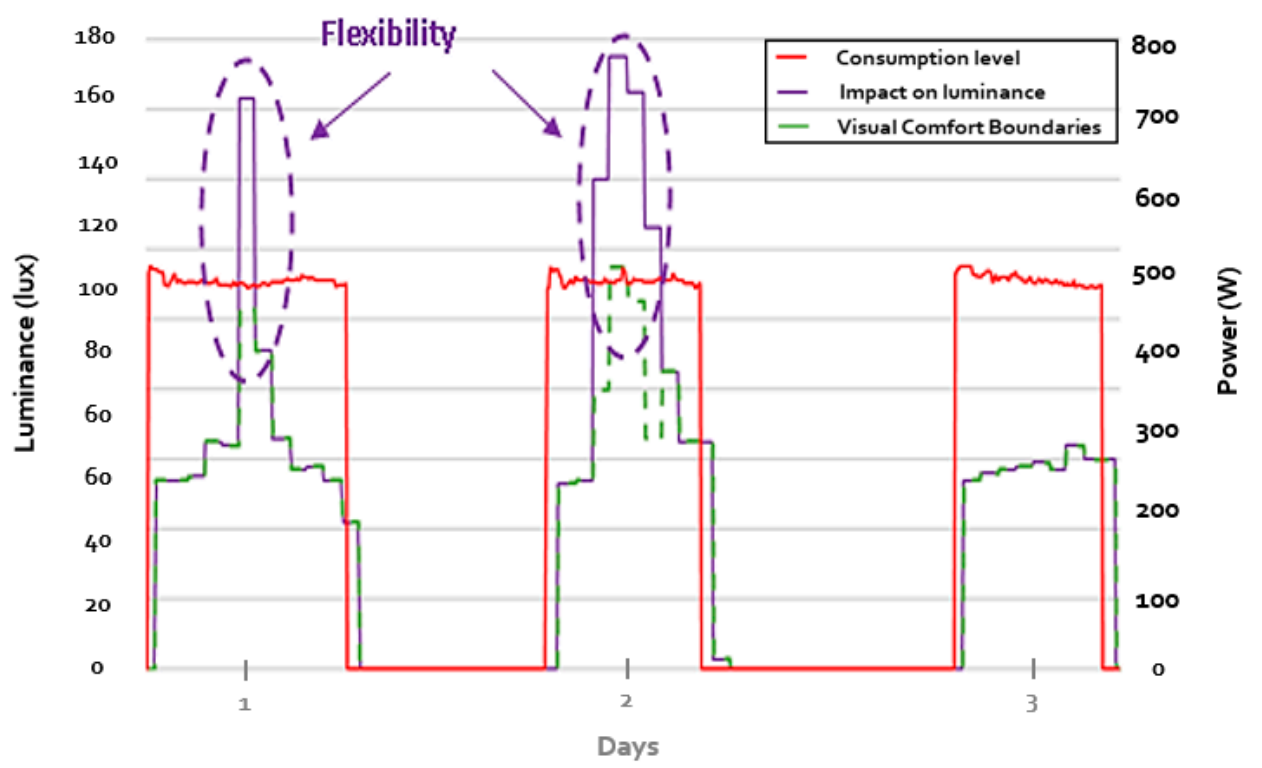

Figure 12. Visual comfort flexibility.

Accordingly, by extracting the model parameters, the operation of the HVAC system was emulated to quantify the potential flexibility. The consumption of HVAC devices was characterized by nominal operating characteristics and environmental (external/internal) operating conditions. Regarding the nominal operating characteristics, Figure 13 indicates the operation of the HVAC system during a two hour-period (HEATING MODE) based on Equation (3). Once the device was turned ON, there was an increase in indoor temperature and an impact in terms of consumption (red curve). This association of consumption-temperature was considered when extracting the model parameters ( $R$ and $C$ ) of the aforementioned equation.

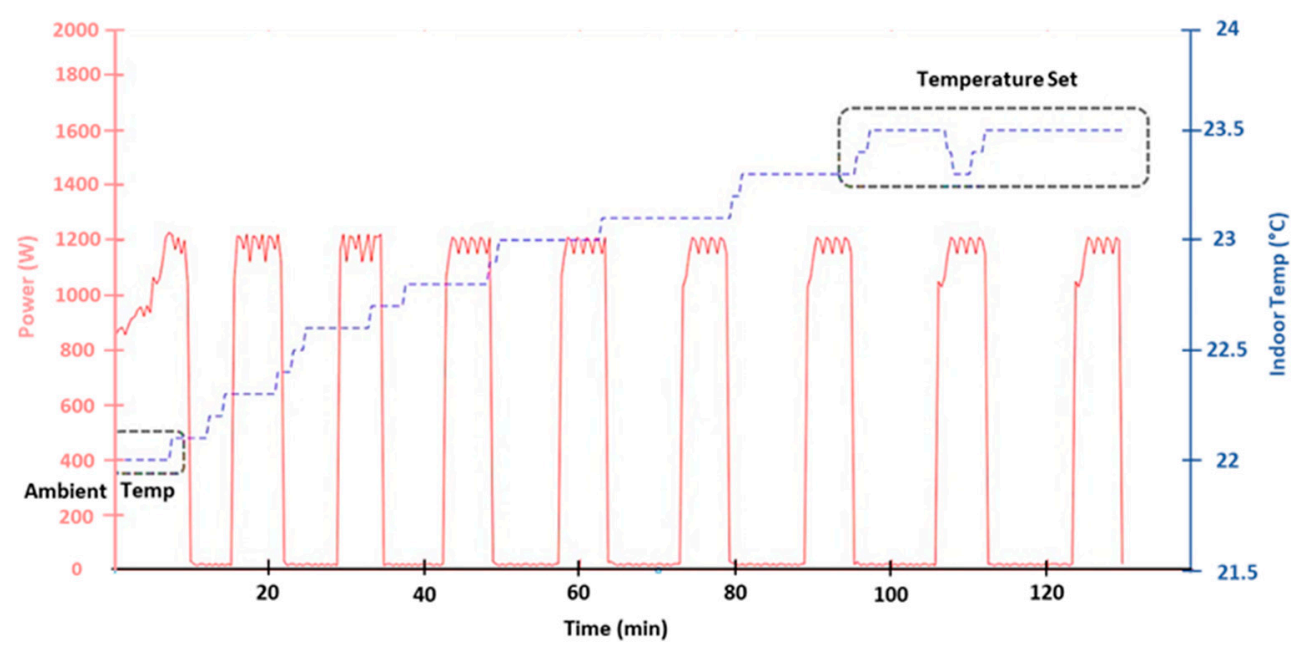

Figure 13. HVAC $2 \mathrm{~h}$ consumption profile.

Figure 14 indicates the different consumption profiles of the HVAC devices while considering the demand flexibility potential based on the environmental conditions. The consumptions of the AC device for set-points of, for example, $25^{\circ} \mathrm{C}$ (in orange) and $24{ }^{\circ} \mathrm{C}$ (in blue) are depicted while maintaining the constraint of the user comfort boundaries. The excess consumption between the setpoints for the same device indicates the potential of flexibility (green). 


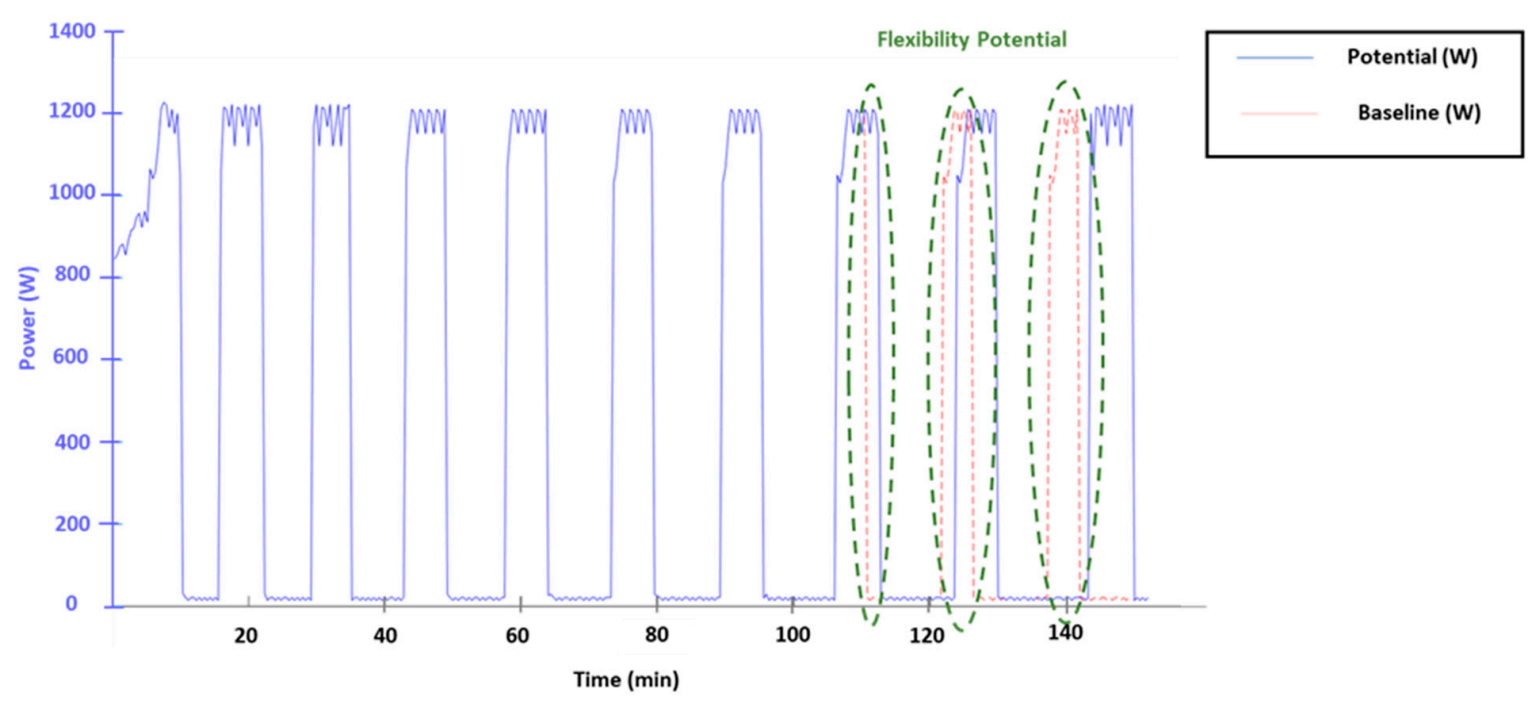

Figure 14. Thermal comfort flexibility.

According to the methodology, business processes were correlated with the lighting and office devices profiles in the extraction of business process-related demand flexibility. One of the key points was that the consumption of office equipment was directly related to the business processes that took place. The consumption in non-operational hours (off-time consumption-consumption when a business process is not performed) was an indication of energy waste/vampire power load with the margin for energy savings. An analysis for an office device appliance (Online Resource 7) is presented in Figure 15. In this case, there was a clear definition of the different states of the plug device based on Equation (4), where the ON state indicated the nominal phase of the device and the OFF phase and the standby mode were associated with the other discrete states of the device. In a five-day analysis, there were specific phases during each day where the device should have been turned off (during non-working hours, as indicated from BPM analysis), even though they operated in standby (marked in green). This excess of use was transformed into flexibility values for this specific DER.

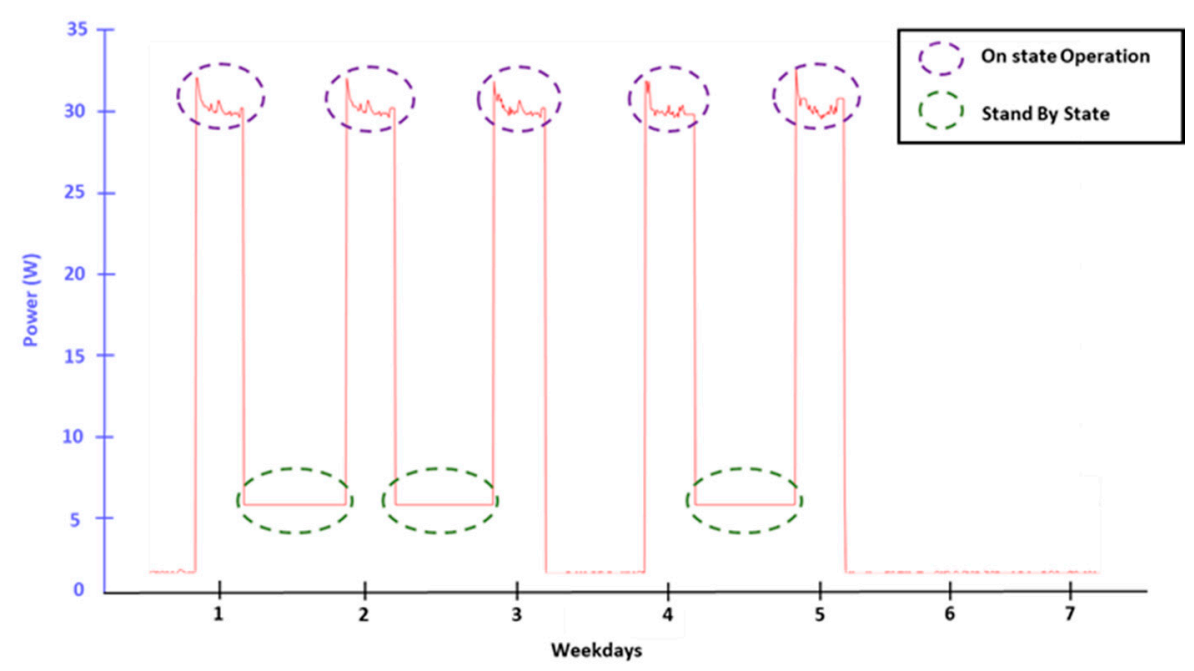

Figure 15. Business processes and Personal Computer (PC)/monitor consumption flexibility analysis.

A similar approach also applied to lighting units (Figure 16). In a five-day analysis, there were specific phases during each day where the lights should have been turned off (during non-working hours, as indicated from BPM analysis), even though they operated in full mode (marked in green). This excess of use was transformed into flexibility values for this specific DER. 


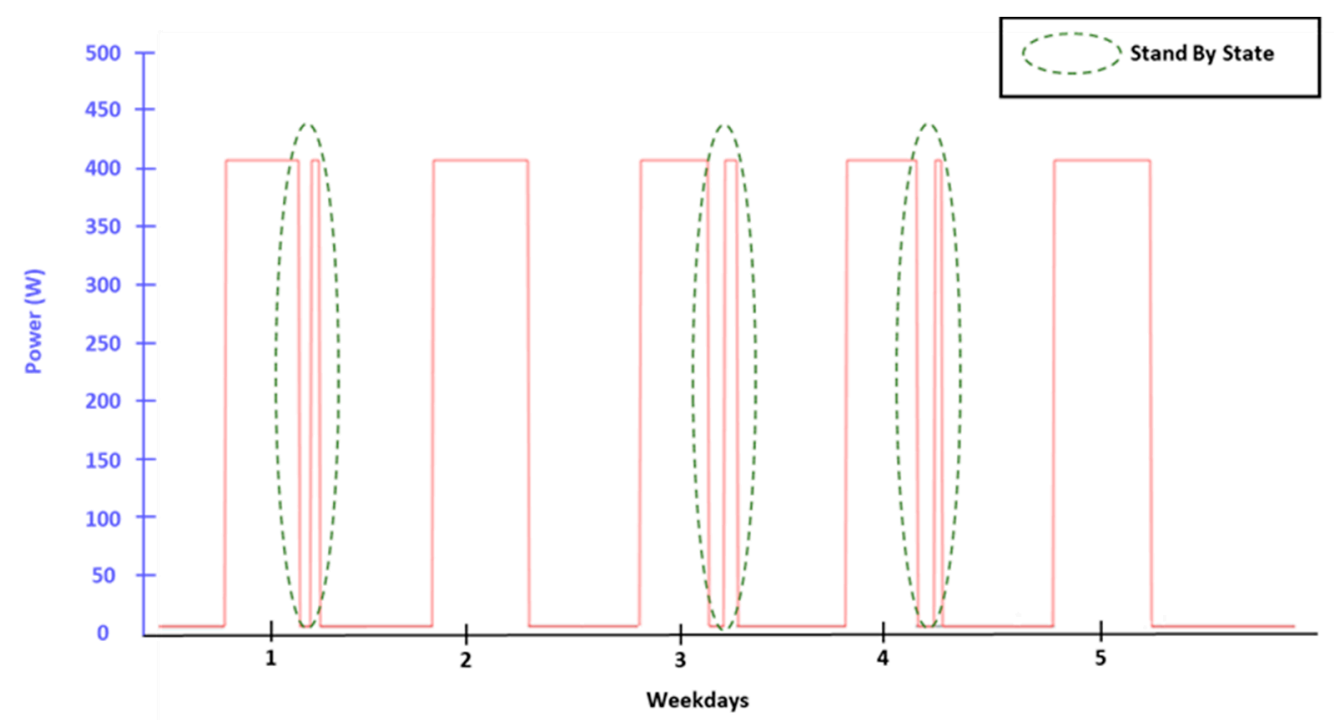

Figure 16. Business processes and lighting consumption flexibility.

\subsubsection{Demand Flexibility Calculation}

The analysis and calculation for flexibility profiles was performed for the individual zones based on the algorithmic processes (Figures 6-8) (Online Resources 6 and 8). The composition of the two approaches contributed to the calculation of the overall flexibility, which was $166 \mathrm{kwh}$. It could be concluded that most of the flexibility was derived from the research office, zone 1 (mostly due to HVAC usage), with $27.16 \mathrm{kwh}$, and public transactions office, zone 6 (mostly due to lighting), with $27.44 \mathrm{kwh}$. The results for all zones are summarized in Table 9.

Table 9. Flexibility results.

\begin{tabular}{|c|c|c|c|c|c|c|c|c|}
\hline \multirow[b]{2}{*}{ Offices } & \multirow[b]{2}{*}{ Zone } & \multicolumn{3}{|c|}{ Comfort Demand Flexibility Analysis } & \multicolumn{3}{|c|}{ Business Process Flexibility Analysis } & \multirow[b]{2}{*}{$\begin{array}{c}\text { Total Savings } \\
\text { (kwh) }\end{array}$} \\
\hline & & $\begin{array}{c}\text { HVAC } \\
(\%)\end{array}$ & $\begin{array}{l}\text { Lights } \\
(\%)\end{array}$ & $\begin{array}{l}\text { Total Savings } \\
\text { (Wh) }\end{array}$ & $\begin{array}{c}\text { Office } \\
\text { Appliances (\%) }\end{array}$ & $\begin{array}{l}\text { Lights } \\
(\%)\end{array}$ & $\begin{array}{l}\text { Total Savings } \\
\text { (Wh) }\end{array}$ & \\
\hline \multirow{4}{*}{ Research Offices } & 1 & $7.08 \%$ & $10.94 \%$ & 21693 & $5.19 \%$ & $0.00 \%$ & 5471 & 27.164 \\
\hline & 2 & $6.06 \%$ & $6.00 \%$ & 18865 & $4.70 \%$ & $0.00 \%$ & 3758 & 22.263 \\
\hline & 3 & $4.25 \%$ & $8.97 \%$ & 16660 & $4.37 \%$ & $0.18 \%$ & 2487 & 19.147 \\
\hline & 4 & $4.26 \%$ & $15.27 \%$ & 15981 & $4.45 \%$ & $0.32 \%$ & 2168 & 18.149 \\
\hline $\begin{array}{c}\text { Public Transactions } \\
\text { Offices }\end{array}$ & 6 & $5.24 \%$ & $14.87 \%$ & 24164 & $6.34 \%$ & $0.86 \%$ & 5280 & 27.444 \\
\hline \multirow{2}{*}{$\begin{array}{l}\text { Administration } \\
\text { Offices }\end{array}$} & 7 & $5.67 \%$ & $7.05 \%$ & 13805 & $4.04 \%$ & $0.57 \%$ & 3131 & 16.936 \\
\hline & 8 & $4.44 \%$ & $10.16 \%$ & 12226 & $4.35 \%$ & $0.38 \%$ & 2302 & 14.528 \\
\hline
\end{tabular}

\section{Discussion and Conclusions}

To truly understand how a building uses and consumes energy, one needs to go beyond its structural characteristics and theoretical models that assess its energy performance based on the intrinsic parameters of its envelope and static elements (such as heating, ventilation, and lighting). Business operations (process organization and management) are an inseparable part of overall business services, as well as overall enterprise energy consumption. Apart from building components (architectural, electrical, and mechanical), multiple levels of information such as environmental conditions (outdoor and indoor) and occupant behavior patterns mostly driven by everyday business processes (schedules, loads, and specific business episodes related to occupancy patterns and building operations) are considered to be necessary for the effective and efficient modeling of building energy performance. Given the trend towards low energy buildings, actively engaging occupants during the building operation is critical to achieve a high energy efficiency without sacrificing end-users' comfort or productivity. 
The aim of this paper was to propose an energy management framework to enable the alignment of fine-grain building energy use data to organizational operational activities in order to extract useful insights about the energy demand flexibility in buildings in order to monitor and control organizational energy performance. The extracted knowledge was derived from correlating fundamental operational aspects (equipment utilization) and environmental conditions (humidity, luminance, and temperature) with occupants' behavior underlying organizational processes and structures. Having multiple sets of data of consumption per business process could result in high energy-consuming business process prioritization. The insights gained from this methodology comprise a knowledge base in order to design and implement appropriate energy efficiency strategies in buildings. The concept of business process integration with energy efficiency acts a tool for business analysts to proceed with process re-engineering with the aim of making processes energy efficient.

Based on the results of the pilot site demo evaluation, the two main points of interest for demand flexibility were found to be HVAC and lighting, which provided the system with maximum values of $7.08 \%$ and $19.46 \%$ of energy savings, respectively, while there was a maximum of $6.34 \%$ saving related to office appliances based on the business process flexibility analysis. Other business process key performance indicators, e.g., lead time, could be also considered in the future. According to the results (Table 9), it can be concluded that:

- User energy profiles can be used for room and devices arrangement purposes in order to achieve better spatial usage. The cooling-heating unit flexibility is considerably larger in absolute size due to the size of the load in a building arrangement. However, in percentage analysis, the flexibility margin is limited (the thermostat provides a wide range of control to the end-user).

- The flexibility of the lighting units is considerably larger in percentage by virtue of the load flexibility (when there is a dimming margin) in a building arrangement. There is a need for dimming for greater control flexibility in a building facility.

- The loss rate is fixed for typical office spaces due to the non-idle operation of the devices in non-operational conditions.

- The loss rate for lighting is limited to non-operational modes.

The above list of high-level guidelines is the framework for designing an energy management system based on the extraction of useful insights. When considering comfort demand flexibility, cooling/heating flexibility is useful in the case of demand shifting from peak time periods, where capacity constraints are binding, to off-peak time periods. Meanwhile, the flexibility of lighting units in the case of demand-shedding strategies takes advantage of dimming technologies as opposed to simply ON/OFF strategies.

The implementation of the proposed framework in larger scale can be secured by combining the following characteristics:

- Modular gateway configuration capable of installing a count of metrics $(\mathrm{N} * 256$ metric devices).

- Modular development of sub-systems with the ability to process large amounts of data.

- Development of sub-systems in a central cloud infrastructure that allows for application expandability in a dynamic way.

- Expandability to a larger installation

- Interoperability.

- Use of standard protocols to incorporate information about the building facility Green Building XML schema (gbXML).

- Use of standard protocols for the incorporation of operational functions information Business Process Model and Notation (BPMN).

- Use of standard protocols to incorporate information about the metric data.

- Functionality expandability.

- Development of additional applications for modeling human behavior in the building environment. 
$<$ xs:element name $=$ "name" type $=$ "xs:string" $\mid>$

$<$ xs:element name $=$ "status" type $=$ "xs:string" $>>$

$<$ xs:element name $=$ "nominalpower" type $=$ "xs:string"/>

$</$ xs:sequence $>$

$</$ xs:complexType $>$

$</$ xs:element $>$

$<$ xs:element maxOccurs="unbounded" name="business_process" $>$

$<$ xs:complexType $>$

$<$ xs:sequence $>$

$<$ xs:element name $=$ "name" type $=$ "xs:string" $\mid>$

$<$ xs:element name $=$ "minDuration" type $=$ "xs:string" $\mid>$

$<$ xs:element name="duration" type="xs:string" $\mid>$

$<$ xs:element name $=$ "starttime" type $=$ "xs:string" $/>$

$<$ xs:element name $=$ "endtime" type $=$ "xs:string" $/>$

$<$ xs:element name $=$ "type" type $=$ "xs:string" $/>$

$<$ xs:element name $=$ "day" type $=$ "xs:string" $\mid>$

$<$ xs:element minOccurs=" 0 " maxOccurs="unbounded" name $=$ "assdevice" $>$

$<$ xs:complexType $>$

$<x$ s:attribute name="deviceIdRef" type="xs:unsignedByte" use="required" $\mid>$

$</$ xs:complexType $>$

$</$ xs:element $>$

$</$ xs:sequence $>$

$</$ xs:complexType $>$

$</$ xs:element $>$

$<$ xs:element name $=$ "construction" $>$

$<$ xs:complexType $>$

$<$ xs:sequence $>$

$<$ xs:element name $=$ "area" type $=$ "xs:decimal" $\mid>$

$<$ xs:element name $=$ "volume" type $=$ "xs:decimal" $\mid>$

$<$ xs:element maxOccurs="unbounded" name $=$ "CartesianPoint" $>$

$<$ xs:complexType $>$

$<$ xs:sequence $>$

$<$ xs:element maxOccurs $=$ "unbounded" name $=$ "Coordinate" type $=$ "xs:decimal" $\mid>$

$</$ xs:sequence $>$

$</$ xs:complexType $>$

$</$ xs:element $>$

$</$ xs:sequence $>$

$</$ xs:complexType $>$

$</$ xs:element $>$

$</$ xs:sequence $>$

$</$ xs:complexType $>$

$</$ xs:element $>$

$</$ xs:sequence $>$

$</$ xs:complexType $>$

$</$ xs:element $>$

$</$ xs:sequence $>$

$</$ xs:complexType $>$

$</$ xs:element $>$

$</$ xs:schema $>$ 


\section{References}

1. European Commission. Sustainable, Secure and Affordable Energy for Europeans; Publications Office of the European Union: Brussels, Belgium, 2012.

2. Kamat, V.R.; Menassa, C.C.; Lee, S. On-line simulation of building energy processes: Need and research requirements. In Proceedings of the 2013 Winter Simulations Conference (WSC), Washington, DC, USA, 8-11 December 2013; IEEE Press: Piscataway, NJ, USA, 2013; pp. 3008-3017.

3. Delzendeh, E.; Wu, S.; Lee, A.; Zhou, Y. The impact of occupants' behaviours on building energy analysis: A research review. Renew. Sustain. Energy Rev. 2017, 80, 1061-1071. [CrossRef]

4. Lopes, M.A.R.; Antunes, C.H.; Martins, N. Energy behaviors as promoters of energy efficiency: A 21st century review. Renew. Sustain. Energy Rev. 2012, 16, 4095-4104. [CrossRef]

5. Bourgeois, D.; Reinhart, C.; Macdonald, I. Adding advanced behavioural models in whole building energy simulation: A study on the total energy impact of manual and automated lighting control. Energy Build. 2006, 38, 814-823. [CrossRef]

6. Hoes, P.; Hensen, J.L.M.; Loomans, M.G.L.C.; de Vries, B.; Bourgeois, D. User behaviour in whole building simulation. Energy Build. 2009, 41, 295-302. [CrossRef]

7. Keyvanfar, A.; Shafaghat, A.; Majid, M.Z.A.; Lamit, H.; Ali, K.N. Correlation Study on User Satisfaction from Adaptive Behavior and Energy Consumption in Office Buildings. J. Teknol. 2014, 70, 89-97. [CrossRef]

8. Rafsanjani, H.N.; Ahn, C.R. Linking building energy-load variations with occupants' energy-use behaviors in commercial buildings: Non-intrusive occupant load monitoring (NIOLM). Procedia Eng. 2016, 145, 532-539. [CrossRef]

9. Lin, Y.; Yang, W.; Gabriel, K.S. A Study on the Impact of Household Occupants' Behavior on Energy Consumption Using an Integrated Computer Model. Front. Built Environ. 2015, 1, 16. [CrossRef]

10. Morton, A.; Reeves, A.; Bull, R.; Preston, S. Empowering and Engaging European building users for energy efficiency. Energy Res. Soc. Sci. 2020, 70, 101772. [CrossRef]

11. Yang, B.; Li, X.; Hou, Y.; Meier, A.; Cheng, X.; Choi, J.-H.; Wang, F.; Wang, H.; Wagner, A.; Yan, D.; et al. Non-invasive (non-contact) measurements of human thermal physiology signals and thermal comfort/discomfort poses-A review. Energy Build. 2020, 224, 110261. [CrossRef]

12. Liu, J.; Yao, R.; Wang, J.; Li, B. Occupants' behavioral adaptation in workplaces with non-central heating and cooling systems. Appl. Therm. Eng. 2012, 35, 40-54. [CrossRef]

13. Shaikh, P.H.; Nor, N.B.M.; Nallagownden, P.; Elamvazuthi, I.; Ibrahim, T. A review on optimized control systems for building energy and comfort management of smart sustainable buildings. Renew. Sustain. Energy Rev. 2014, 34, 409-429. [CrossRef]

14. Jang, H.; Kang, J. A stochastic model of integrating occupant behaviour into energy simulation with respect to actual energy consumption in high-rise apartment buildings. Energy Build. 2016, 121, 205-216. [CrossRef]

15. Dietz, T.; Gardner, G.T.; Gilligan, J.M.; Stern, P.C.; Vandenbergh, M.P. Household actions can provide a behavioral wedge to rapidly reduce US carbon emissions. Proc. Natl. Acad. Sci. USA 2009, 106, 18452-18456. [CrossRef] [PubMed]

16. Nguyen, T.A.; Aiello, M. Energy intelligent buildings based on user activity: A survey. Energy Build. 2013, 56, 244-257. [CrossRef]

17. Ghaffarianhoseini, A.; Berardi, U.; Al Waer, H.; Chang, S.; Halawa, E.; Ghaffarianhoseini, A.; Clements-Croome, D. What is an intelligent building? Analysis of recent interpretations from an international perspective. Archit. Sci. Rev. 2016, 59, 338-357. [CrossRef]

18. GhaffarianHoseini, A.; Dahlan, N.D.; Berardi, U.; GhaffarianHoseini, A.; Makaremi, N.; GhaffarianHoseini, M. Sustainable energy performances of green buildings: A review of current theories, implementations and challenges. Renew. Sustain. Energy Rev. 2013, 25, 1-17. [CrossRef]

19. Crawley, D.B.; Hand, J.W.; Kummert, M.; Griffith, B.T. Contrasting the capabilities of building energy performance simulation programs. Build. Environ. 2008, 43, 661-673. [CrossRef]

20. Chassiakos, A.P.; Karatzas, S.K. Process Centric Building Energy Management-As-A-Service. In Proceedings of the International Conference on Smart Infrastructure and Construction 2019 (ICSIC), Cambridge, UK, 8-10 July 2019; pp. 11-20. [CrossRef]

21. Caicedo, D.; Pandharipande, A.; Willems, F.M. Daylight-adaptive lighting control using light sensor calibration prior-information. Energy Build. 2014, 73, 105-114. [CrossRef] 
22. Bomela, W.; Zlotnik, A.; Li, J.-S. A phase model approach for thermostatically controlled load demand response. Appl. Energy 2018, 228, 667-680. [CrossRef]

23. Raj, P.A.D.V.; Sudhakaran, M.; Raj, P.P.-D.-A.; Polytechnic, P.M.N.G. Estimation of Standby Power Consumption for Typical Appliances. J. Eng. Sci. Technol. Rev. 2009, 2, 71-75. [CrossRef]

24. ANSI/ASHRAE. Thermal Environmental Conditions for Human Occupancy, Standard 55-2004; American Society of Heating, Refrigerating and Air-Conditioning Engineers, Inc.: Atlanta, GA, USA, 2005.

25. Ghose, A.; Hoesch-Klohe, K.; Hinsche, L.; Lê, L.-S. Green business process management: A research agenda. Australas. J. Inf. Syst. 2010, 16, 103-117. [CrossRef]

26. Liu, L.; Wang, H.; Liu, X.; Jin, X.; He, W.B.; Wang, Q.B.; Chen, Y. GreenCloud: A new architecture for green data center. In Proceedings of the 6th International Conference Industry Session on Autonomic Computing and Communications Industry Session, Barcelona, Spain, 15-19 June 2009; ACM: Barcelona, Spain, 2009; pp. 29-38.

27. Reiter, M.; Fettke, P.; Loos, P. Towards green business process management: Concept and implementation of an artifact to reduce the energy consumption of business processes. In Proceedings of the 2014 47th Hawaii International Conference on System Sciences, Waikoloa, HI, USA, 6-9 January 2014; IEEE: Piscataway, NJ, USA, 2014; pp. 885-894.

Publisher's Note: MDPI stays neutral with regard to jurisdictional claims in published maps and institutional affiliations.

(C) 2020 by the authors. Licensee MDPI, Basel, Switzerland. This article is an open access article distributed under the terms and conditions of the Creative Commons Attribution (CC BY) license (http://creativecommons.org/licenses/by/4.0/). 